\title{
Prefácio
}

A Comunidade Ibero-

-Americana de Ciências da

Comunicação: Publicar em

Português e em Espanhol,

Difundir Conhecimento

https://doi.org/10.21814/uminho.ed.43.1

\section{Moisés de Lemos Martins}

Centro de Estudos de Comunicação e Sociedade, Instituto de Ciências Sociais, Universidade do Minho, Portugal 

Em 2010, o Conselho Científico das Ciências Sociais e das Humanidades (CCCSH) da Fundação para a Ciência e Tecnologia (FCT), do Estado português, era presidido pelo historiador José Mattoso. E elaborou, em 2011, um programa estratégico nacional, de aplicação em Portugal até 2020, para o desenvolvimento e a consolidação desta vasta área científica, em torno de uma agenda com os seguintes tópicos: internacionalização, pluralismo, pluridisciplinaridade, avaliação, disseminação do conhecimento.

Para o elaborar, o CCCSH reuniu-se, ao longo do ano de 2011, com os responsáveis das 132 unidades desta área transdisciplinar, então existentes em Portugal, o que nunca havia acontecido na história da FCT, e não voltou acontecer, até ao dia de hoje.

A proposta de política científica apresentada contraria o atual modelo hegemónico de fazer ciência, um modelo que apaga a Ibero-América, tanto pela língua de uso, como pelo paradigma científico que lhe impõe. Na política científica joga-se, com efeito, um verdadeiro combate, pela ordenação simbólica do mundo (Bourdieu, 1977, $1979,1982)$, onde se colocam os problemas da língua hegemónica e da subordinação política, científica, cultural e artística (Martins, 2015). E realizando este combate, proposto em 2011 pelo Conselho Científico das Ciências Sociais e das Humanidades da FCT, estaríamos a dar oportunidades ao conhecimento, que se exprime na diversidade das culturas faladas em Português e em Espanhol, assim concorrendo para a construção de uma comunidade científica, policentrada e polifacetada, uma comunidade com sentido humano, que é sempre uma comunidade com o sentido do debate e da cooperação, no respeito pela diversidade e pela diferença entre as culturas (Brito \& Martins, 2005).

Relembro algumas das recomendações feitas neste documento, de 2011, do CCCSH da FCT, que nos interessam particularmente.

Dinamizar, com as congéneres espanhola e da América Latina, uma base de dados bibliométrica da qual façam parte as revistas científicas que cumpram as normas da European Science Foundation (e.g., quanto à componente internacional do "editorial board"), embora aceitem o espanhol e o português, a par do inglês, como línguas de publicação; Incluir nos indicadores de internacionalização: (i) a autoria conjunta de trabalhos científicos por investigadores nacionais e estrangeiros; (ii) o impacto das publicações; (...) Promover a cooperação científica com os PALOP [Países Africanos de Língua Oficial Portuguesa], os países da bacia mediterrânica e os países emergentes com os quais Portugal mantém laços históricos e culturais, nomeadamente das políticas científicas e tecnológicas dos estados membros da CPLP. (Mattoso et al., 2011, p. 11) 
Este plano, formulado em Portugal pela FCT, em 2011, conjugava-se na perfeição com os objetivos científicos formulados pelas associações nacionais de Ciências da Comunicação dos países ibero-americanos, reunidas na cidade do Funchal (ilha da Madeira), em abril de 2009. Esse compromisso científico resultou, então, na constituição da Confederação Ibero-americana de Associações Científicas e Académicas de Comunicação (Confibercom) ${ }^{1}$. E os congressos e fóruns da Confibercom, que depois se realizaram, em São Paulo (2011), Quito (2012), Porto (2013), Braga (2014), São Paulo (2015), foram suportados por três equipas de investigação transnacionais, uma sobre política científica, outra sobre a pós-graduação, e uma outra sobre divulgação do conhecimento, através de publicações (revistas e livros) ${ }^{2}$. Cada equipa de investigação compreendia cinco a seis investigadores, garantindo a presença de um investigador brasileiro, um outro investigador da América do Sul, um investigador da América do Norte, Central e Caraíbas, um investigador espanhol e um investigador português ${ }^{3}$.

As políticas de ciência, língua e cultura, e também o modo como elas modelam e condicionam o desenvolvimento das comunidades lusófonas e ibero-americanas de Ciências Sociais e Humanas, supõem, todavia, que consideremos o atual contexto da globalização do conhecimento e da cultura digital, e que façamos juntos uma travessia de "circum-navegação tecnológica" (Martins, 2018). Com efeito, sendo tecnológica a condição da época, o ciberespaço passou a ser um novo lugar do conhecimento científico (Maffesoli \& Martins, 2011), sem dúvida em língua inglesa, com as políticas de comunicação a saltar para os sites, os portais eletrónicos, as redes sociais, os repositórios digitais e os museus virtuais; mas do ponto de vista que nos interessa, 0 novo lugar do conhecimento tem de ser, também, em língua portuguesa, assim como em língua espanhola (Martins, 2017a; Martins \& Oliveira, 2013a).

No entanto, ainda mal começou o combate pela conversão das línguas, portuguesa e espanhola, como línguas de conhecimento e de ciência. São as políticas linguísticas dos países lusófonos e ibero-americanos, assim como as políticas de comunicação científica, que decidem quem tem o poder de definir a realidade social, assim como

\footnotetext{
${ }^{1}$ A Confibercom tem site próprio: http://confibercom.com/ . Mas também pode ser consultada alguma informação neste endereço: http://polobs.pt/basedados/confibercom-confederacao-ibero-americanade-associacoes-cientificas-e-academicas-de-comunicacao/

${ }^{2}$ A Confibercom realizou dois congressos, um na Universidade de São Paulo, em 2011; e um outro na Universidade do Minho, em Braga, em 2014. Realizou também três fóruns, um em Quito (2012), outro no Porto (2013); e um outro ainda em São Paulo (2015). Sobre esta atividade científica foram publicados os seguintes livros: Kunsch e Melo (2012); Kunsch (2013); e Martins (2017a). O congresso de Braga publicou, ainda, um livro de atas: Martins e Oliveira (2014).

${ }^{3}$ Depois do fórum da Confibercom, realizado em São Paulo (2015), a Confibercom reformulou os seus objetivos, no decorrer do congresso da Asociación Española de Investigación de la Comunicación (AEIC), realizado em Madrid, em 2016, e passou a integrar a dinâmica dos congressos Ibercom, realizados pela Associação Ibero-americana de Comunicação (Assibercom). Foi assim, em 2017, no "XV Congresso Ibercom”, realizado em Lisboa, e no “XVI Congresso Ibercom”, realizado em Bogotá, em 2019.
} 
o poder de impor essa representação. E tanto as políticas científicas, como as políticas da comunicação da ciência, estão hoje inteiramente nas mãos dos governos nacionais, ficando reservado para as comunidades científicas um papel praticamente residual (Martins, 2012a, 2017b). E de acordo como o modelo hegemónico, ciência é, em síntese, o que é publicado (1) em Inglês; (2) sob a forma de artigos em revistas científicas; (3) em artigos, que obedecem ao formato IMRaD (introduction, methods, results, and discussion [introdução, métodos, resultados e discussão]); e (4) publicado em revistas científicas com "fator de impacto" (Serra, 2017). Esta hegemonia do Inglês como língua exclusiva de ciência tem contribuído para a estandardização do pensamento e do conhecimento. E os países de língua portuguesa e de língua espanhola não fogem à regra. Também neles os pesquisadores publicam, cada vez mais, em Inglês e as citações são feitas, tendencialmente, a partir de artigos e livros publicados em Inglês ${ }^{4}$.

Neste contexto, as consequências para os interesses das comunidades de investigação em Ciências Sociais e Humanas, lusófonas e ibero-americanas, têm sido desastrosos, sobretudo porque as suas próprias comunidades científicas estão muito longe de encarar como necessário o combate que estabeleça as línguas, portuguesa e espanhola, como línguas de ciência. Dou como exemplo os resultados do estudo levado a cabo por Paulo Serra sobre aquilo que ele considera ser "O (des)conhecimento recíproco dos investigadores ibero-americanos de Ciências da Comunicação", publicado na Revista Lusófona de Estudos Culturais/Lusophone Journal of Cultural Studies (Serra, 2016).

António Castilho et al. (2012) vão mais longe ao afirmarem que é muito problemático o desafio que o mundo latino-americano tem diante de si para credibilizar e indexar as suas revistas científicas. Propulsados pelo Inglês como língua hegemónica, o processo de indexação das revistas científicas e o "fator de impacto", aliados à necessidade de "sobreviver na selva académica", têm conduzido a práticas científicas perversas, que estão a destruir a integridade da ciência e das universidades (Martins, 2015; Nóvoa, 2014). Veja-se, a este propósito, Allen Wihite e Eric Fong (2015), quando denunciam a "manipulação de citações"; e também, o bibliotecário e ativista Jeffrey Beall (2015), manifestando-se contra os "editores predatórios". Na expressão, um tanto hiperbólica, de George Monbiot (2011) ao The Guardian, os

\footnotetext{
${ }^{4}$ Sobre todas estas questões, veja-se o número da Revista Lusófona de Estudos Culturais/Lusophone Journal of Cultural Studies consagrado à "Ciência e conhecimento: políticas e discursos" (Martins et al., 2016). Veja-se, também, Gradim e Moura (2015) e Gradim e Morais (2016). Veja-se, ainda, "As Ciências da Comunicação e o mundo lusófono" (Martins, 2016); "A liberdade académica e os seus inimigos" (Martins, 2015); "Interview with Moisés de Lemos Martins" (Martins, 2013); "Revistas científicas de Ciências da Comunicação em Portugal: da divulgação do conhecimento à afirmação do Português como língua de pensamento e conhecimento" (Martins, 2012b); "Política científica de Comunicação em Portugal: desafios e oportunidades para os doutoramentos" (Martins \& Oliveira, 2013b); "As Ciências Sociais e a política científica" (Martins, 2008); Ensino superior e melancolia (Martins, 2002).
} 
editores de ciência são "os capitalistas mais implacáveis no mundo ocidental" (para. 1). Foi, aliás, o custo exorbitante do conhecimento que levou Aaronson et al. (2012) a desencadear o movimento de boicote a revistas, como as da Elsevier, e à adoção de outras formas de publicação ${ }^{5}$.

Como bem referia, em 2011, o CCCSH da FCT, presidido por José Mattoso, o que faria mesmo sentido para os países de línguas, portuguesa e espanhola, seria a criação de um sistema de avaliação das revistas, nacionais e internacionais, controlado pela comunidade académica. Passaram 10 anos. E parece muito longo, ainda, o caminho que nos falta percorrer.

\section{Agradecimentos}

Este trabalho é apoiado por fundos nacionais através da FCT - Fundação para a Ciência e a Tecnologia, I.P., no âmbito do projeto UIDB/00736/2020.

\section{Referências}

Aaronson, S., Arnold, D. N., Avila, A., Baez, J., Bornemann, F., Calegari, D., Cohn, H., Daubechies, I., Ellenberg, J., Emerton, M., Farge, M., Gabai, D., Gowers, T., Green, B., Grötschel, M., Harris, M., Hélein, F., Kirby, R., Lafforgue, V., ... Ziegler, G. M. (2012). The cost of knowledge. https://people.math.ethz.ch/ wewerner/elsevierstatementfinal.pdf

Beall, G. (2015). Os editores predatórios estão a destruir a integridade da comunicação académica. In A. Gradim \& C. Moura (Eds.), Comunicar e avaliar ciência (pp. 11-30). Labcom.IFP. http://labcom.ubi.pt/livro/248

Bourdieu, P. (1977). Sur le pouvoir symbolique. Annales, 32(3), 405-411.

Bourdieu, P. (1979). La distinction. Critique sociale du jugement. Éditions de Minuit.

Bourdieu, P. (1982). Ce que parler veut dire. Fayard.

Brito, R., \& Martins, M. L. (2005). Moçambique e Timor-Leste: Onde também se fala o português. In A. Fidalgo \& P.Serra (Eds.), Ciências da comunicação em congresso na Covilhã:Actas do III Sopcom, VI Lusocom e II Ibérico (Vol 3, pp. 641-648). Universidade da Beira Interior. http://hdl.handle.net/1822/1005

Castillo, A., Almansa, A., \& Álvarez, A.(2012). Pesquisa latino-americana em Comunicação. Estudo bibliométrico de revistas científicas. In M. Kunsch \& J. M. Melo (Eds.), Comunicação ibero-americana: Sistemas midiáticos, diversidade cultural, pesquisa e pós-graduação (pp. 385-400). Confibercom; Escola de Comunicação e Artes da Universidade de São Paulo.

Gradim, A., \& Morais, R. (2016). Anões aos ombros de gigantes. Desafios contemporâneos na comunicação de ciência. Livros Horizonte.

\footnotetext{
${ }^{5}$ Retomo nestes dois últimos parágrafos o meu estudo "Para uma comunidade científica policentrada e polifacetada, uma comunidade com sentido humano" (2017c, pp. 32-34).
} 
Gradim, A., \& Moura, C. (Eds.). (2015). Comunicar e avaliar ciência. Labcom.IFP.

Kunsch, M. (Ed.). (2013). La comunicación en Iberoamérica: Políticas científicas y tecnológicas, posgrado y difusión de conocimiento. CIESPAL; Confibercom.

Kunsch, M., \& Melo, J. M. (Eds.). (2012). Comunicação ibero-americana: Sistemas midiáticos, diversidade cultural, pesquisa e pós-graduação. Confibercom; Escola de Comunicação e Artes da Universidade de São Paulo.

Maffesoli, M., \& Martins, M. (2011). Ciberculturas. Revista de Comunicação e Linguagens, 42, 41-52. http://hdl. handle.net/1822/23794

Mattoso, J., Alvelos, H., Duarte, I., Ferrão, J., Amaral, J. F., Lima, L. P., Mesquita, P. E., Perez, Maria, R., \& Koulaidis, V. (2011). Ciências sociais e humanidades: Mais excelência, maior impacte. Conselho Científico das Ciências Sociais e das Humanidades. https://www.fct.pt/conselhos_cientificos/docs/rel_final_CCCSH_2011.pdf

Martins, M. L. (2002). Ensino superior e melancolia. Instituto Politécnico de Viana do Castelo. http://hdl.handle.net/1822/1288

Martins, M. L. (2008). As ciências sociais e a política científica. In A. Torres \& L. Baptista (Eds.), Sociedades contemporâneas. Reflexividade e acção (pp. 27-29). Afrontamento. http://hdl.handle.net/1822/1059

Martins, M. L. (2012a). A política científica e tecnológica em Portugal e as ciências da comunicação: Prioridades e indecisões. In M. Kunsch \& J. M. Melo (Eds.), Comunicação ibero-americana: Sistemas midiáticos, diversidade cultural, pesquisa e pós-graduação (pp. 331-345). Confibercom; Escola de Comunicação e Artes da Universidade de São Paulo. http://hdl.handle.net/1822/23931

Martins, M. L. (2012b). Revistas científicas de ciências da comunicação em Portugal: Da divulgação do conhecimento à afirmação do Português como língua de pensamento e conhecimento. Intercom - Revista Brasileira de Ciências da Comunicação, 35(1),233-251. http://hdl.handle.net/1822/23768

Martins, M. L. (2013). Interview with Moisés de Lemos Martins. In Z. Pinto-Coelho \& A. Carvalho (Eds.), Academics responding to discourses of crisis in higher education and research (pp. 61-72). CECS. http://hdl.handle. net/1822/29224

Martins, M. L. (2015). A liberdade académica e os seus inimigos. Comunicação e Sociedade, 27, 405-420. https://doi.org/10.17231/comsoc.27(2015).2109

Martins, M. L. (2016). Ciências da comunicação e mundo lusófono. Anuário Internacional de Comunicação Lusófona, 13, 11-18. http://hdl.handle.net/1822/45164

Martins, M. L. (Ed.). (2017a). A internacionalização das comunidades lusófonas e ibero-americanas de ciências sociais e humanas - O caso das ciências da comunicação. Húmus. http://hdl.handle.net/1822/49365

Martins, M. L. (2017b). Comunicação da ciência, acesso aberto do conhecimento e repositórios digitais - 0 futuro das comunidades lusófonas e ibero-americanas de ciências sociais e humanas. In M. L. Martins (Ed.), A internacionalização das comunidades lusófonas e ibero-americanas de ciências sociais e humanas - O caso das ciências da comunicação (pp. 19-58). Húmus. http://hdl.handle.net/1822/51039

Martins, M. L. (2017c). Para uma comunidade científica policentrada e polifacetada, uma comunidade com sentido humano. In M. L. Martins (Ed.), A internacionalização das comunidades lusófonas e ibero-americanas de ciências sociais e humanas - O caso das ciências da comunicação (pp. 11-15). Húmus. http://hdl.handle. net/1822/51037 
Martins, M. L. (2018). Os países lusófonos e o desafio de uma circum-navegação tecnológica. Comunicação e Sociedade, 34, 87-101. https://doi.org/10.17231/comsoc.34(2018).2937

Martins, M. L., Baptista, M. M., Araújo, E., \& Latif. L. (Eds.) (2016). Ciência e conhecimento: Políticas e discursos [Edição temática]. Revista Lusófona de Estudos Culturais, 3(2). https://rlec.pt/index.php/rlec/issue/view/96

Martins, M. L. \& Oliveira, M. (2013a). Doctorado e investigación sobre comunicación en Portugal: Panorama, retos y oportunidades. Revista Latinoamericana de Ciencias de la Comunicación, 10, 238-265. http://www.alaic. net/revistaalaic/index.php/alaic/article/view/429

Martins, M. L., \& Oliveira, M. (2013b). Política científica de comunicação em Portugal: Desafios e oportunidades para os doutoramentos. In M. Kunsch (Eds.), La comunicación en Iberoamérica: Políticas científicas y tecnológicas, postgrado y difusión de conocimiento (pp. 47-101). Ciespal; Confibercom.

Martins, M. L., \& Oliveira, M. (Eds.). (2014). Comunicação Ibero-americana: Os desafios da internacionalização - Livro de atas do II Congresso Mundial de Comunicação Ibero-americana. CECS. http://hdl.handle. net/1822/33031

Monbiot, G. (2011, 29 de agosto). Academic publishers make Murdoch look like a socialist. The Guardian. https://www.theguardian.com/commentisfree/2011/aug/29/academic-publishers-murdoch-socialist

Nóvoa, A. (2014). Em busca da liberdade nas universidades: Para que serve a investigação em Educação? Revista Lusófona de Educação, 28(28), 11-21. https://revistas.ulusofona.pt/index.php/rleducacao/article/ view/4936

Serra, P. (2016). O (des)conhecimento recíproco dos investigadores ibero-americanos de ciências da comunicação. Revista Lusófona de Estudos Culturais, 3(2), 57-68. https://doi.org/10.21814/rlec.115

Serra, P. (2017). As línguas francas em ciência e a questão dos paradigmas. In M. L. Martins (Ed.), A internacionalização das comunidades lusófonas e ibero-americanas de ciências sociais e humanas - $O$ caso das ciências da comunicação (pp. 261-276). Húmus. http://www.lasics.uminho.pt/ojs/index.php/cecs_ebooks/article/ view/2724

Wilhite,A., \& Fong, E. (2015). Por Albert Einstein, o editor, você, e eu. In A. Gradim \& C. Moura (Eds.), Comunicar e avaliar ciência (pp. 31-46). Labcom.IFP. http://labcom.ubi.pt/livro/248 